\title{
Characterization of Thiol-Functionalised Silica Films Deposited on Electrode Surfaces
}

\author{
Ivana Cesarino, Éder Tadeu Gomes Cavalheiro* \\ Instituto de Química de São Carlos, Universidade de São Paulo - USP, \\ Av. do Trabalhador Sancarlense, 400, 13565-590 São Carlos - SP, Brazil
}

Received: September 8, 2008; Revised: November 11, 2008

\begin{abstract}
Thiol-functionalised silica films were deposited on various electrode surfaces (gold, platinum, glassy carbon) by spin-coating sol-gel mixtures in the presence of a surfactant template. Film formation occurred by evaporation induced self-assembly (EISA) involving the hydrolysis and (co)condensation of silane and organosilane precursors on the electrode surface. The characterization of such material was performed by IR spectroscopy, thermogravimetry (TG), elemental analysis (EA), atomic force microscopy (AFM), scanning electron microscopy (SEM) and cyclic voltammetry (CV).
\end{abstract}

Keywords: silica films, 3-mercaptopropyltrimethoxysilane, evaporation induced self-assembly

\section{Introduction}

Organofunctionalised mesoporous silica materials are of great interest because they combine a high surface area and a narrow pore size distribution with the advantage of owing organic ligand properties. This expands the range of potential applications in catalysis, sensors, separation and opto-electric devices ${ }^{1-5}$. Such materials can be prepared by one-pot co-condensation of organotrialkoxysilane and tetraalkoxysialne. One-pot synthesis of functionalised thin layers requires the Evaporation-Induced-Self-Assembly (EISA) process, which was reported to be particularly suited for the preparation of nicely ordered hybrid mesoporous thin films ${ }^{6}$, even in electrode surfaces ${ }^{7}$, in which a large variety of organic moieties can be incorporated ${ }^{8}$.

Zhao et al. have described how surfactant and non-aqueous cosolvents can be used to define mesophase structure ${ }^{1,9,10}$. Interestingly, the templating approach prevents the appearance of cracks into the film, even after surfactant removal. Extraction of the surfactant from ordered mesoporous films led to a large increase of mass transport rates into the materials and imparted high accessibility to the organic moieties of organofunctionalised mesoporous overlayers ${ }^{11}$.

Silica-based organic-inorganic hybrid materials have become increasingly used in the fields of electroanalytical chemistry ${ }^{12-14}$ and the characterization of these new materials is very important in the understanding of electrodes modification..

In this work a one-step synthesis of organofunctionalised cetyltrimethylammonium bromide (CTAB)-template silica thin films, using 3-mercaptopropyltrimethoxysilane (MPTMS) like an organotrialkoxysilane is presented. The polymeric silica sols were deposited by spincoating approach on freshly polished gold, platinum and glassy carbon surfaces. The characterization of such material was performed by IR spectroscopy, thermogravimetry (TG) and elemental analysis (EA) to evaluate the organofunctionalisation of the sol-gel film. The surface of the electrodes modified with thiol-functionalised silica film (TFSF) was also characterized by atomic force microscopy (AFM), scanning electron microscopy (SEM) and cyclic voltammetry (CV).

\section{Experimental}

\subsection{Reagents and solutions}

The chemicals were of analytical grade and used without further purification. Tetraethoxysilane 95\% (TEOS, Acros Organics, USA), 3-mercaptopropyltrimethoxysilane 85\% (MPTMS, Acros Organics, USA), cetyltrimethylammonium bromide $98 \%$ (CTAB, Vetec, Brazil), ethanol 99.5\% (Synth, Brazil) and $\mathrm{HCl} 37 \%$ (Qhemis, Brazil) were used for the preparation of sol solutions.

\subsection{Preparation of the electrodes}

The polymeric silica sols were typically prepared by heating a mixture of $2.08 \mathrm{~g}$ TEOS, including selected equivalent fractions (up to $20 \%$ ) of MPTMS, $5.5 \mathrm{~g} \mathrm{EtOH}, 0.5 \mathrm{~g}$ water and $0.4 \mathrm{~g}$ of a $0.1 \mathrm{~mol} . \mathrm{L}^{-1}$ $\mathrm{HCl}$ solution, at $70{ }^{\circ} \mathrm{C}$ for 1 hour, to which $0.78 \mathrm{~g}$ of CTAB dissolved in $10 \mathrm{~g}$ of $\mathrm{EtOH}$ was then added and stirred again for 1 hour at room temperature ${ }^{15}$.

The activation of the glassy carbon electrode surface previously to the deposition of the sol-gel film was performed by cycling potentials in a phosphate buffer ${ }^{16}$ and helped in improving significantly the mechanical stability of the carbon/silica interface. Thus after activation twenty microliter of sol was deposited on glassy carbon electrode surface and on freshly polished gold, platinum electrodes surface (all $3 \mathrm{~mm}$ in diameter), which were rotated at $7000 \mathrm{rpm}$ for 15 seconds. This procedure was repeated five times. The spin-coated films were then kept for 30 minutes at $60^{\circ} \mathrm{C}$ in an oven under reduced pressure.

The surfactant extraction was performed in a 1.0 mol. $\mathrm{L}^{-1} \mathrm{HCl}$ ethanol solution under hydrodynamic conditions (rotating the electrode at $150 \mathrm{rpm}$ ) for 15 minutes $^{11}$.

\subsection{Apparatus}

Elemental analysis (EA) was performed in an EAGER-200 apparatus (CE Instruments) and IR spectra were obtained in a Nicolet 5SXC spectrometer in the 500-4000 $\mathrm{cm}^{-1}$ range. Films with and without the modifier were prepared in a Petri plate coverted with an aluminum foil and dried under an incandescent light, during 3 hours. Then they were transferred to a mortar and powdered. The resulting powders were analyzed by EA. The powder was pressed and IR spectra were taken directly from the resulting thin pellets.

Thermogravimetric curves were recorded in a TGA-951 modulus (TA Instruments) using $7 \mathrm{mg}$ of sample in a platinum crucible at $10{ }^{\circ} \mathrm{C} / \mathrm{min}$ heating rate under air dynamic atmospheres (flow $100 \mathrm{~mL} / \mathrm{min}$ ). 
Scanning electron microscopy (SEM) images were recorded in a LEO-440 (Leica-Zeiss) microscope using $20 \mathrm{kV}$ electronic bean and magnification of 300x and atomic force microscopy (AFM) images were obtained in the contact mode with an Explorer equipment from Topometrix Inc.

Voltammetric experiments were performed using a BAS-CV $50 \mathrm{~W}$ potentiostat. A three-electrode cell $(20.0 \mathrm{~mL}$ full capacity) was used with an $\mathrm{Ag} / \mathrm{AgCl}$ and a platinum wire $(\varnothing=1 \mathrm{~mm} ; 1=20 \mathrm{~mm})$ as the reference and auxiliary electrodes, respectively. All the measurements were taken at room temperature without deaeration.

\section{Results and Discussion}

Thiol-functionalised silica films were synthesized and deposited on the conducting substrates via the sol-gel process. TEOS $\left(\mathrm{Si}\left(\mathrm{OC}_{2} \mathrm{H}_{5}\right)_{4}\right)$ and MPTMS $\left(\mathrm{HSC}_{3} \mathrm{H}_{6} \mathrm{Si}\left(\mathrm{OCH}_{3}\right)_{3}\right)$ were used for that purpose. The general procedure involves two successive steps: the hydrolysis (Equations 1a and 1b) and (co)condensation (Equations $2 \mathrm{a}$ and $2 \mathrm{~b}$ ) of the precursors. Both steps occurring consecutively and sometimes concomitantly.

$$
\begin{aligned}
& \mathrm{Si}\left(\mathrm{OC}_{2} \mathrm{H}_{5}\right)_{4}+\mathrm{nH}_{2} \mathrm{O} \underline{\mathrm{H}^{+}} \\
& \mathrm{Si}\left(\mathrm{OC}_{2} \mathrm{H}_{5}\right)_{(4-\mathrm{n})}(\mathrm{OH})_{\mathrm{n}}+\mathrm{nC}_{2} \mathrm{H}_{5} \mathrm{OH} \\
& \mathrm{HSC}_{3} \mathrm{H}_{6} \mathrm{Si}\left(\mathrm{OCH}_{3}\right)_{3}+\mathrm{nH}_{2} \mathrm{O} \underline{\mathrm{H}^{+}} \\
& \mathrm{HSC}_{3} \mathrm{H}_{6} \mathrm{Si}\left(\mathrm{OCH}_{3}\right)_{(3-\mathrm{n})}(\mathrm{OH})_{\mathrm{n}}+\mathrm{nCH}_{3} \mathrm{OH} \\
& \mathrm{Si}\left(\mathrm{OC}_{2} \mathrm{H}_{5}\right)_{(4-\mathrm{n})}(\mathrm{OH})_{\mathrm{n}} \underline{\mathrm{OH}} \\
& \mathrm{Si}\left(\mathrm{OC}_{2} \mathrm{H}_{5}\right)_{(4-\mathrm{n})}(\mathrm{OH})_{(\mathrm{n}-1)} \mathrm{O}+\mathrm{H}_{2} \mathrm{O} \\
& \mathrm{Si}\left(\mathrm{OC}_{2} \mathrm{H}_{5}\right)_{(4-\mathrm{n})}(\mathrm{OH})_{(\mathrm{n}-1)} \mathrm{O}+ \\
& \mathrm{HSC}_{3} \mathrm{H}_{6} \mathrm{Si}\left(\mathrm{OCH}_{3}\right)_{(3-\mathrm{n})}(\mathrm{OH})_{\mathrm{n}} \underline{\mathrm{OH}} \\
& \mathrm{HSC}_{3} \mathrm{H}_{6} \mathrm{Si}\left(\mathrm{OCH}_{3}\right)_{(3-\mathrm{n})} \mathrm{OSi}\left(\mathrm{OC}_{2} \mathrm{H}_{5}\right)_{(4-\mathrm{n})}(\mathrm{OH})_{(\mathrm{n}-1)}+ \\
& \mathrm{H}_{2} \mathrm{O}
\end{aligned}
$$

Elemental analysis, IR spectroscopy and thermogravimetry were employed for evaluating the organofunctionalisation of sol-gel. EA presented an increase in the carbon and hydrogen contents and sulfur appeared after modification. Sols containing 10 and $15 \%$ of mercaptopropyl groups, according to the MPTMS/TEOS ratio in the starting sol-gel were synthesized and is possible to observe an increase in the sulfur contents in the sol-gel containing $15 \%$ of mercaptopropyl groups in relation to the $10 \%$ MPTMS. The elemental analysis data are presented in Table 1 and revealead the changes in the content of each element after each functionalisation step. The carbon content was used to estimate the number of mols of modifier per $100 \mathrm{~g}$ of modified sols ( $\mathrm{n}$ ) in each case. The increase in the carbon and sulfur contents as more MPTMS is used, suggested that the modifier is being incorporated to the sol-gel matrix.

Table 1. Elemental analysis (\%) and number of mol for each element per 100 grams (n) of the sol-gel, sol-gel functionalised with $10 \%$ and $15 \%$ of MPTMS

\begin{tabular}{lcccccc}
\hline \multirow{2}{*}{ Sample } & \multicolumn{2}{c}{$\mathrm{C}$} & \multicolumn{2}{c}{$\mathrm{H}$} & \multicolumn{2}{c}{$\mathrm{S}$} \\
\cline { 2 - 7 } & $\%$ & $\mathrm{n}$ & $\%$ & $\mathrm{n}$ & $\%$ & $\mathrm{n}$ \\
\hline Sol-gel & 31.18 & 2.60 & 6.69 & 6.64 & 0 & 0 \\
Sol-gel/10\%MPTMS & 34.31 & 2.86 & 7.35 & 7.29 & 2.56 & 0.08 \\
Sol-gel/15\% MPTMS & 35.16 & 2.93 & 6.94 & 6.89 & 3.86 & 0.12 \\
\hline
\end{tabular}

Figure 1 presents the IR spectra of sol-gel (curve a) and sol-gel functionalised with $15 \%$ of MPTMS (curve b). The band around $3440 \mathrm{~cm}^{-1}$ could be attributed to the adsorbed water and to the $\mathrm{H}$ bonded silanol $\mathrm{OH}$ groups. IR spectra of surfactant (CTAB) aggregates presented two bands at 2922 and $2854 \mathrm{~cm}^{-1}$ due to the $\mathrm{CH}_{2}$ units asymmetric and symmetric vibrations, respectively ${ }^{17}$. Other bands between 1200 and $500 \mathrm{~cm}^{-1}$ are associated with $\mathrm{Si}-\mathrm{O}-\mathrm{Si}$ or $\mathrm{Si}-\mathrm{OH}$ band vibration of the siliceous framework, e.g., $1080 \mathrm{~cm}^{-1}$ band with the Si-O-Si asymmetric bond stretching vibration and $960 \mathrm{~cm}^{-1}$ band with the Si-OH bond stretching vibration. The methoxy groups of MPTMS are indicated spectrally by a significant decrease in the intensity of the $960 \mathrm{~cm}^{-1}$ band ${ }^{18}$. The band in $580 \mathrm{~cm}^{-1}$ is from thiol group of MPTMS.

Figure 2 presents the termogravimetric curves of sol-gel (curve a) and sol-gel functionalised with $15 \%$ of MPTMS (curve b). The sol-gel and sol-gel/15\% MPTMS presented dehydration at the beginning of the TG curves. However the mass losses are not stoichiometric. In order to compare the mass losses in the samples the decomposition steps were normalized by discounting the dehydration process and considering the dried material as the starting mass. The sol-gel presents a second transition from $249-320{ }^{\circ} \mathrm{C}$ with a mass loss of $52.7 \%$ and a last transition with a mass loss of $5.9 \%$. The sol-gel/15\% MPTMS present a second transition from 233-432 ${ }^{\circ} \mathrm{C}$ with a mass loss of $53.0 \%$ and a last transition with a mass loss of $7.7 \%$. As expected the mass losses observed for the sol-gel and the modified material did not changed markedly. However the decomposition profiles in the region of the organic matter burning, c.a. 200 to $450^{\circ} \mathrm{C}$ are quite different, showing that the modifier promoted changes in the sol-gel.

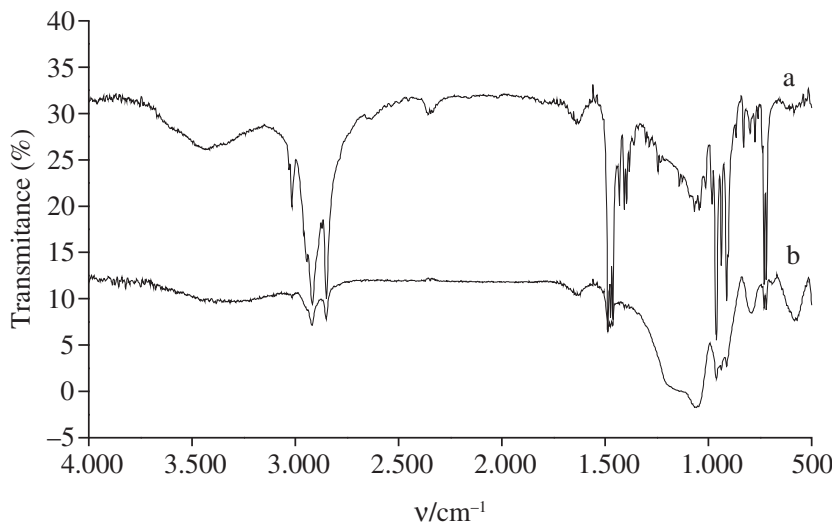

Figure 1. IR spectra: a) sol-gel; and b) sol-gel functionalised with $15 \%$ of MPTMS.

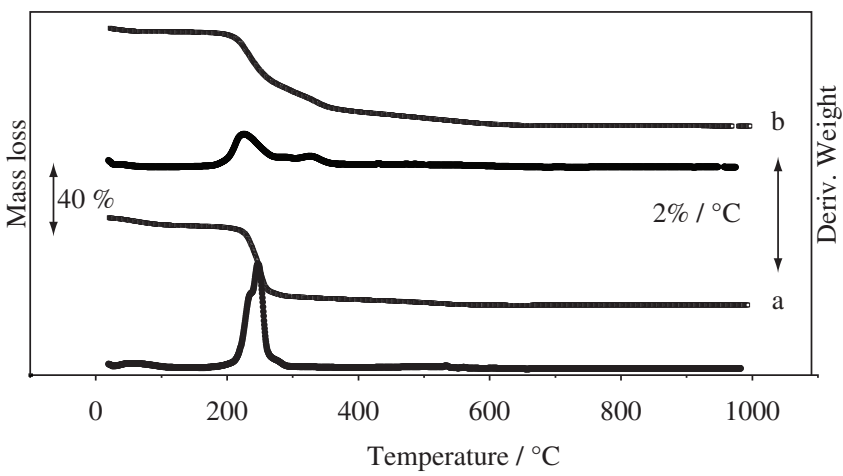

Figure 2. Termogravimetric curves: a) sol-gel and b) sol-gel functionalised with $15 \%$ of MPTMS 
Voltammetric experiments, SEM and AFM images were used to analyse the electrode surface modified with TFSF. AFM images of modified electrodes showed features not present at bare gold, glass carbon and platinum electrodes. The TFSF affect their topography. The image of GC/TFSF reveals that the film grew more uniformly at this surface when compared with Au/TFSF and Pt/TFSF (Figure 3). Rougher films were obtained on the metallic surfaces.

Electronic micrographies revealed significant changes in the morphology of TFSF before and after the extraction of the surfactant, exemplified in Figure 4 for the glassy carbon electrode modified with the film. In agreement with AFM images, the micrography of GC/TFSF showed a more uniform film in this case, mainly after the extraction of the surfactant when a smooth surface was reached.

Typical cyclic voltammograms recorded in hexacyanoferrate solutions are depicted in Figure 5 to compare the response obtained prior

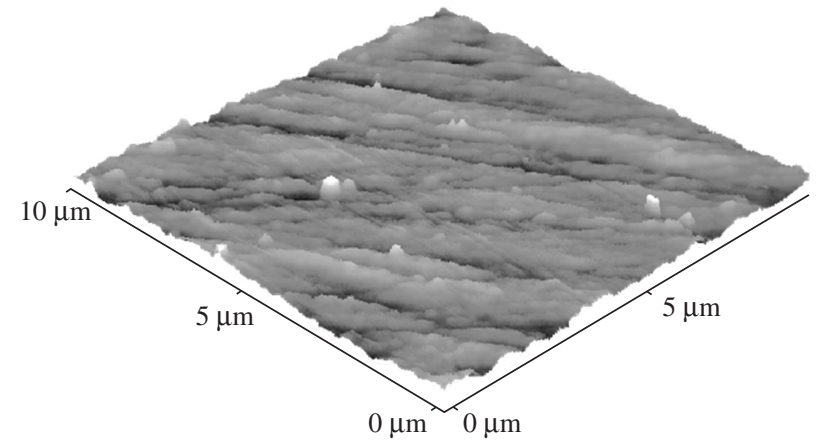

(a)

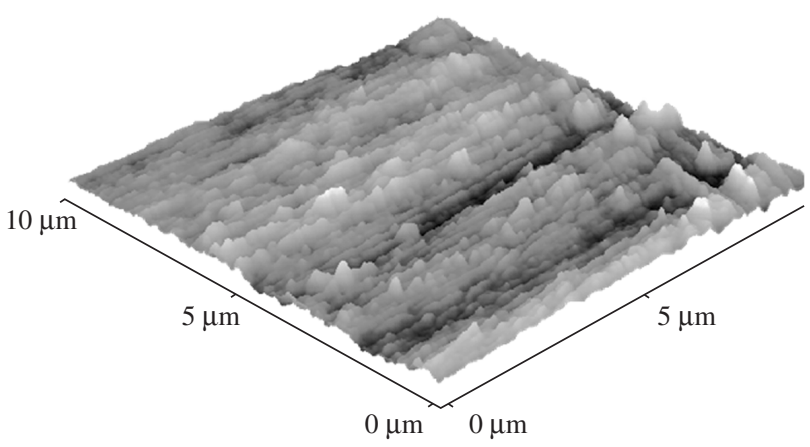

(c)

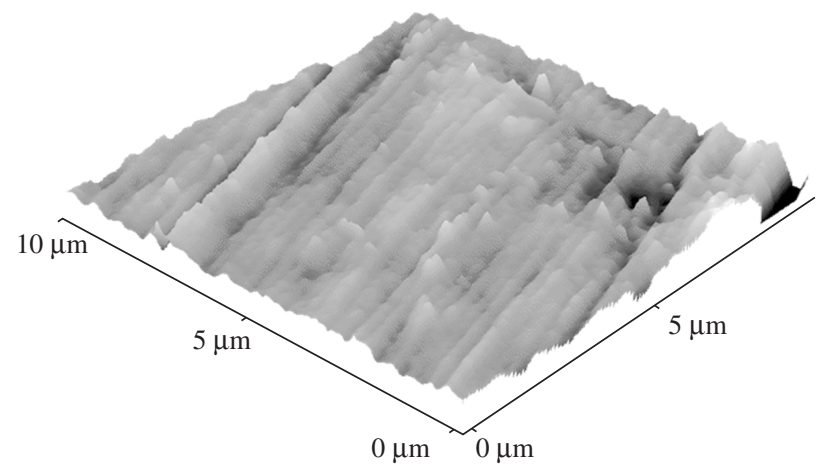

(e) to film deposition (curve a), after templated film deposition (curve b), after surfactant extraction from the film (curve c), and TFSF (curve d). After deposition of the sol-gel film before surfactant removal on gold electrode, the voltammetric signals were suppressed, indicating that the surfactant templated mesoporous film acts as a barrier for the $\mathrm{Fe}(\mathrm{CN})_{6}^{3-}$ redox probes. This suggests the existence of a crack-free film preventing the external solution to reach the electrode surface, even after prolonged immersion times because of the hydrophobic character of the surfactant template located in the mesopores of the silica material.

After template removal by treating the electrode in an ethanol/ $\mathrm{HCl}$ solution, a remarked increase in the $\mathrm{Fe}(\mathrm{CN})_{6}^{3-}$ current was observed, indicating significant permeation properties. The redox probes are now able to cross the mesoporous film to be detected on the electrode surface. Etienne and Walcarius ${ }^{11}$ described that when preparing a thin silica film in the absence of surfactant template,

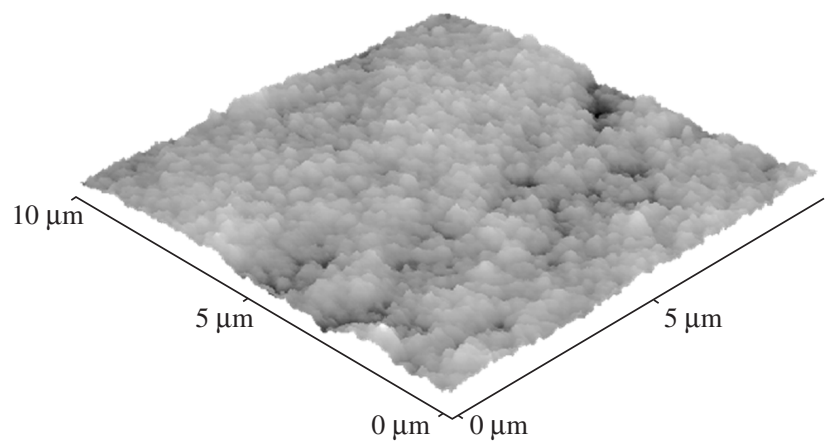

(b)

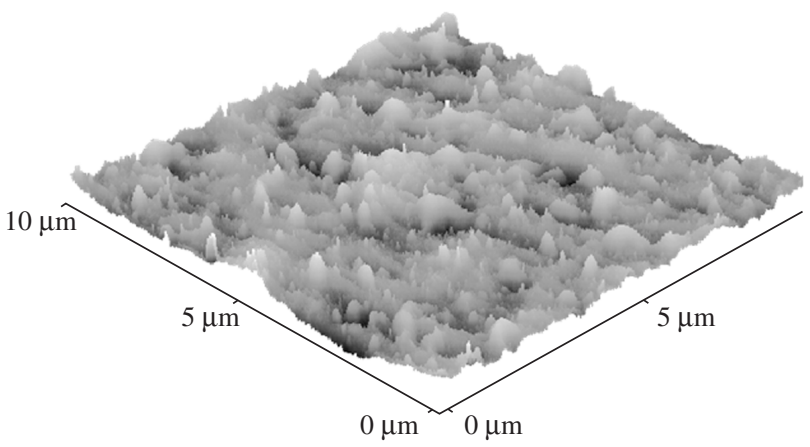

(d)

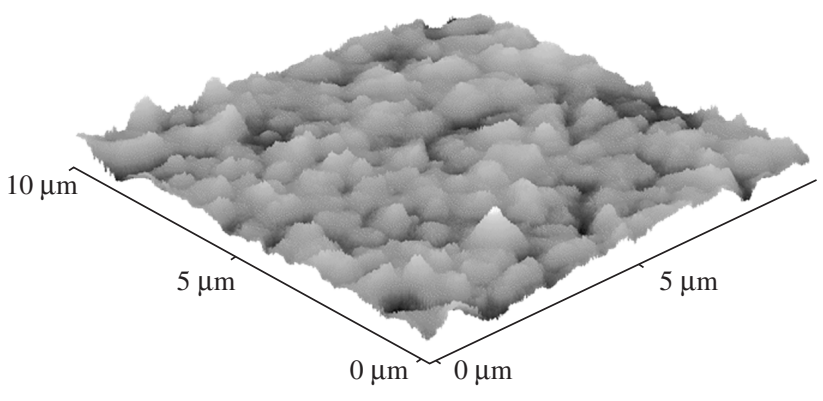

(f)

Figure 3. AFM images a) bare GC, b) GC/TFSF, c) bare Au, d) Au/TFSF e) bare Pt and f) Pt/TFSF. 


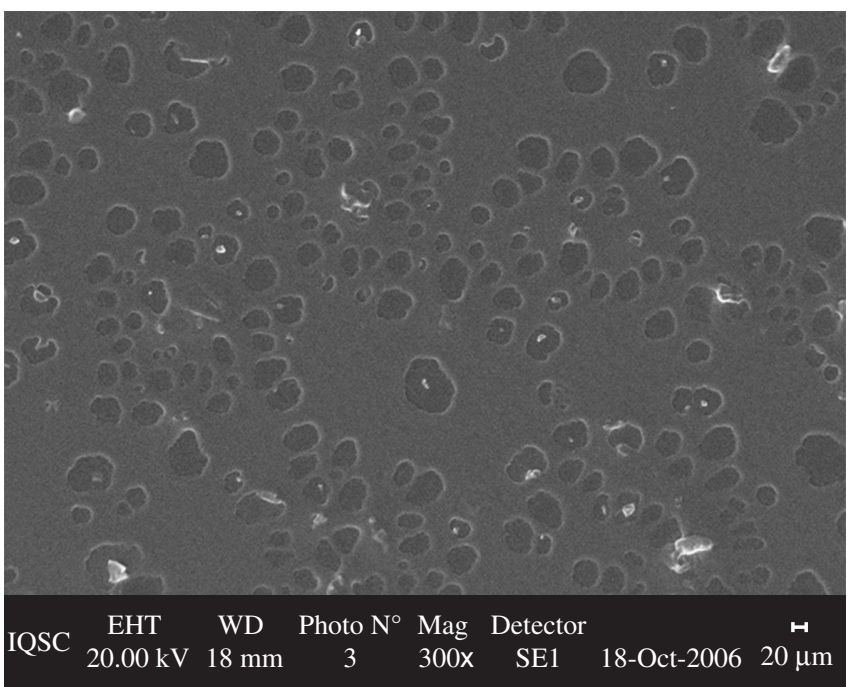

(a)

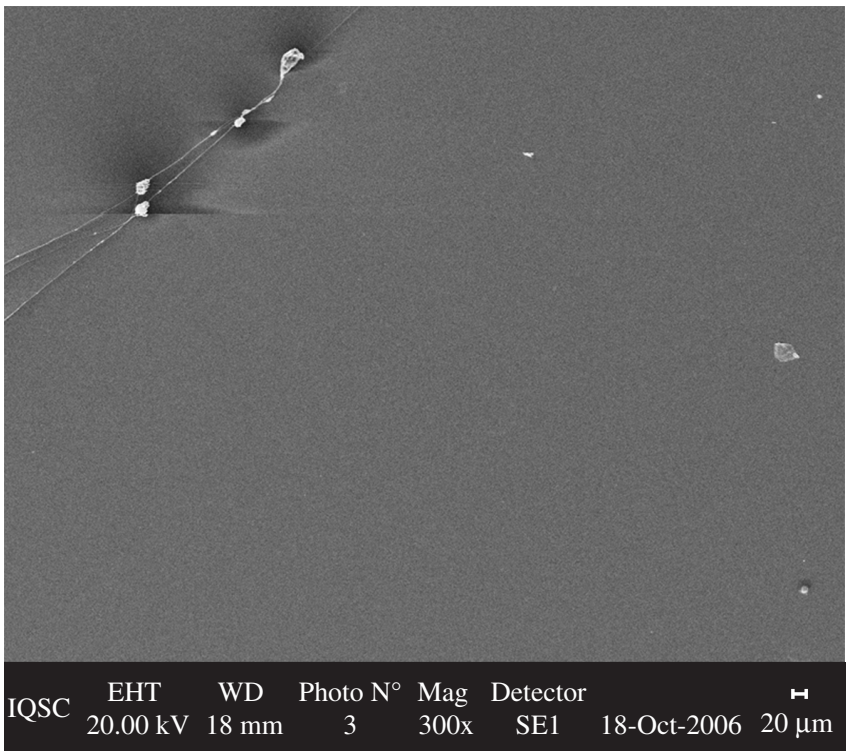

(b)

Figure 4. GC/TFSF micrographies before and a) and after b) the extraction of the surfactant.

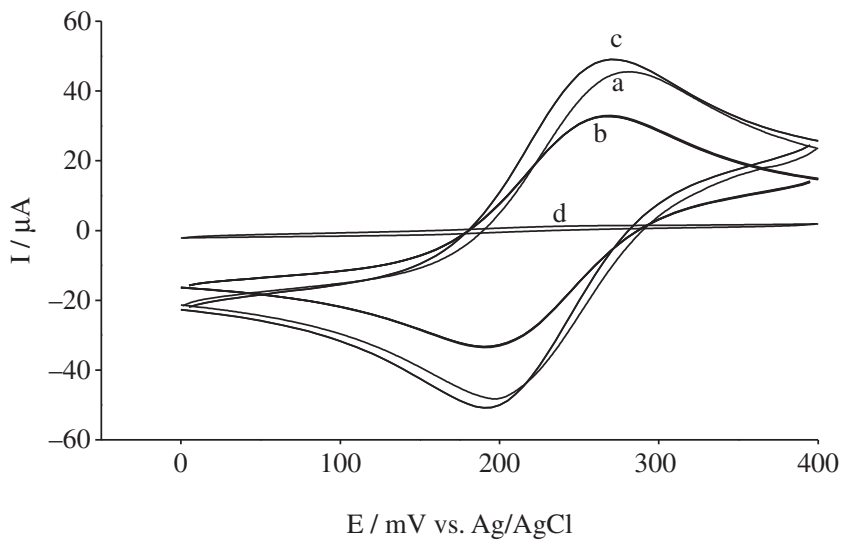

Figure 5. Cyclic voltammetric curves recorded in $5 \mathrm{mM} \mathrm{Fe}(\mathrm{CN})_{6}^{3-}$ using gold electrodes : a) bare $\mathrm{Au}$; b) after deposition of film, c) after surfactant removal and d) Au/TFSF. Voltammograms obtained $50 \mathrm{mV} / \mathrm{s}$ scan rate. the resulting deposit was microporous and nonordered, and was practically non- permeable to the redox probe (current response less than $1 \mu \mathrm{A}$ ). Our results agreed with these findings, illustrating the importance of the template approach to produce highly permeable films.

The behavior of the film electrode containing 15\% of MPTMS reflects the strong interactions existing between the organic groups of the film with the electrode surface, which would induce a control of the electrochemical response by the particular nature of the electrode/ film interface rather than by the mass transfer processes through the mesoporous layer.

The GC/TFSF containing $15 \%$ of mercaptopropyl groups has been tested for accumulation and detection of $\mathrm{Hg}^{2+}$ ions. A sample solution was made of $20 \mu \mathrm{mol} . \mathrm{L}^{-1} \mathrm{Hg}^{2+}$ in 0.1 mol.L ${ }^{-1} \mathrm{HNO}_{3}$. Under these conditions, $\mathrm{Hg}^{2+}$ species can only be adsorbed via a complexation reaction with thiol groups. This preconcentration experiment is a satisfactory way to evaluate the accessibility to the binding sites in the functionalised film.

A typical measurement involves two successive steps: the GC/ TFSF was first immersed into the accumulation medium for 1 minute, then removed, and finally transferred into a detection solution containing $\mathrm{HCl} 3.0$ mol.L $\mathrm{L}^{-1}$ where detection was performed by anodic stripping voltammetry. In this medium, the previously accumulated $\mathrm{Hg}^{2+}$ species complexed by the thiol groups in the open circuit pre-concentration step are then directly reduced at $-0.5 \mathrm{~V}$ during 60 seconds prior to be quantified by a differential pulse anodic scan from -0.5 to $0.3 \mathrm{~V}$ (vs. $\mathrm{Ag} / \mathrm{AgCl}$ ).

A stripping peak appeared at about $-0.06 \mathrm{~V}$ (Figure 6), which is directly proportional to the quantity of analyte previously accumulated into the film. These results are promising in using the GC electrode modified with TFSF can be a useful tool in determining $\mathrm{Hg}^{2+}$ in waters or other, natural samples, in which this metal is a potential pollutant.

\section{Conclusion}

The results showed that the functionalisation of sol-gel with 3-mercaptopropyltrimethoxysilane can be performed and the bare electrodes were modified with thiol-functionalised silica films. The electrochemical properties of the modified electrode are strongly related to the presence of the surfactant and interactions between the modifier and the electrode surface.

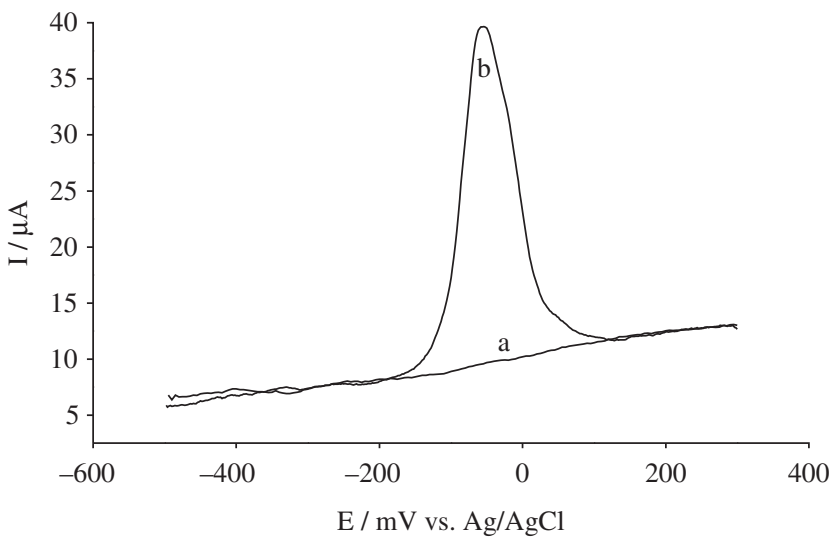

Figure 6. Electrochemical response of GC/TFSF: a) before and b) after 1 minute accumulation of $\mathrm{Hg}^{2+}$ ions in an open-circuit. Scan rate of $10 \mathrm{mV} / \mathrm{s}$ and pulse amplitude of $100 \mathrm{mV}$. 


\section{Acknowledgements}

Authors are indebted to the Brazilian agency CAPES for fellowship and FAPESP for the financial support (08/03537-7) and Dra. Sonia Tomie Tanimoto do Grupo de Materiais e Métodos Eletroanalíticos do IQSC/USP, for the atomic force microscopy images.

\section{References}

1. Zhao DY, Feng JL, Huo QS, Melosh N, Fredrickson GH, Chmelka BF, Stucky GD. Triblock copolymer syntheses of mesoporous silica with periodic 50 to 300 angstrom pores. Science. 1998; 279(5350):548-552.

2. Yang H, Coombs N, Sokolov I, Ozin GA. Free-standing and oriented mesoporous silica films grown at the air-water interface. Nature. 1996; 381(6583):589-592.

3. Aksay IA, Trau M, Manne S, Honma I, Yao N, Zhou L, Fenter P, Eisenberger PM, Gruner SM. Biomimetic pathways for assembling inorganic thin films. Science. 1996; 273(5277):892-898.

4. Ogawa M. Formation of novel oriented transparent films of layered silicasurfactant nanocomposites. Journal of the American Chemical Society. 1994; 116(17):7941-7942.

5. Martin JE, Anderson MT, Odinek J, Newcomer P. Synthesis of periodic mesoporous silica thin films. Langmuir.1997; 13(15):4133-4141.

6. Brinker CJ, Lu YF, Sellinger A, Fan HY. Evaporation-induced selfassembly: Nanostructures made easy. Advanced Materials. 1999; 11(7):579-585

7. Liu NG, Dunphy DR, Atanassov P, Bunge SD, Chen Z, Lopez GP, Boyle TJ, Brinker CJ. Photoregulation of mass transport through a photoresponsive azobenzene-modified nanoporous membrane. Nano Letters. 2004; 4(4):551-554.

8. Nicole L, Boissiere C, Grosso D, Quach A, Sanchez C. Mesostructured hybrid organic-inorganic thin films. Journal of Materials Chemistry. 2005; 15(35-36):3598-3627.
9. Zhao DY, Huo QS, Feng JL, Chmelka BF, Stucky GD. Nonionic triblock and star diblock copolymer and oligomeric surfactant syntheses of highly ordered, hydrothermally stable, mesoporous silica structures. Journal of the American Chemical Society. 1998; 120(24):6024-6036.

10. Huo QS, Zhao DY, Feng JL, Weston K, Buratto SK, Stucky GD, Schacht S, Schuth F. Room temperature growth of mesoporous silica fibers: A new high-surface-area optical waveguide. Advanced Materials. 1997; 9(12):974.

11. Etienne M, Walcarius A. Evaporation induced self-assembly of templated silica and organosilica thin films on various electrode surfaces. Electrochemistry Communications. 2005; 7(12):1449-1456.

12. Cesarino I, Marino G, Matos JD, Cavalheiro ETG. Evaluation of a carbon paste electrode modified with organofunctionalised SBA-15 nanostructured silica in the simultaneous determination of divalent lead, copper and mercury ions. Talanta. 2008; 75(1):15-21.

13. Walcarius A. Electroanalysis with pure, chemically modified, and sol-gelderived silica-based materials. Electroanalysis. 2001; 13(8-9):701-718.

14. Fan HY, Lu YF, Stump A, Reed ST, Baer T, Schunk R, Perez-Luna V, Lopez GP, Brinker CJ. Rapid prototyping of patterned functional nanostructures. Nature. 2000; 405(6782):56-60.

15. Zhao DY, Yang PD, Margolese DI, Chmelka BF, Stucky GD. Synthesis of continuous mesoporous silica thin films with three-dimensional accessible pore structures. Chemical Communications. 1998; (22):2499-2500.

16. Shustak G, Marx S, Turyan I, Mandler D. Application of sol-gel technology for electroanalytical sensing. Electroanalysis. 2003; 15(5-6):398-408.

17. Hua ZL, Shi JL, Wang L, Zhang WH. Preparation of mesoporous silica films on a glass slide: surfactant template removal by solvent extraction. Journal of Non-Crystalline Solids. 2001; 292(1-3):177-183.

18. Thompson WR, Cai M, Ho MK, Pemberton JE. Hydrolysis and Condensation of Self-Assembled Monolayers of (3-Mercaptopropyl) trimethoxysilane on Ag and Au Surfaces. Langmuir. 1997; 13(8):2291-2302. 